\title{
BMJ Open Psychosocial determinants of quit motivation in older smokers from deprived backgrounds: a cross-sectional survey
}

\author{
Pamela Smith (D) , ${ }^{1}$ Rhian Daniel, ${ }^{1}$ Rachael L Murray (D) , ${ }^{2}$ Graham Moore, ${ }^{3}$ \\ Annmarie Nelson, ${ }^{4}$ Kate Brain (i) ${ }^{1}$
}

To cite: Smith P, Daniel R, Murray RL, et al. Psychosocial determinants of quit motivation in older smokers from deprived backgrounds: a cross-sectional survey. BMJ Open

2021;11:e044815. doi:10.1136/ bmjopen-2020-044815

- Prepublication history and supplemental material for this paper is available online. To view these files, please visit the journal online (http://dx.doi. org/10.1136/bmjopen-2020044815).

Received 15 September 2020 Revised 15 February 2021 Accepted 15 April 2021

Check for updates

(C) Author(s) (or their employer(s)) 2021. Re-use permitted under CC BY-NC. No commercial re-use. See rights and permissions. Published by BMJ.

${ }^{1}$ Division of Population Medicine, Cardiff University, Cardiff, UK

${ }^{2} U K$ Centre for Tobacco Control Studies, Division of Epidemiology \& Public Health, University of Nottingham, Nottingham, UK

${ }^{3}$ School of Social Sciences, Cardiff University, Cardiff, UK

${ }^{4}$ Marie Curie Palliative Care

Research Centre, Cardiff University, Cardiff, UK

Correspondence to

Pamela Smith;

smithp18@cardiff.ac.uk

\section{ABSTRACT}

Objectives To identify psychosocial determinants of quit motivation in older deprived smokers. The evidence may be used to optimise smoking cessation interventions for the target population.

Design Cross-sectional survey using online recruitment methods including Facebook-targeted advertising.

Setting UK, 2019.

Participants Current smokers aged 50 years or older and from a socioeconomically deprived background.

Main outcome measures Measures included motivation to stop smoking, smoking history, perceived social support, self-efficacy for quitting, self-exempting beliefs and lung cancer risk perception. Multivariable regression was used to analyse factors associated with quit motivation.

Results Of a total 578 individuals who consented to take part, 278 (48.1\%) did not meet the inclusion criteria. Of the 300 eligible participants, most were recruited using Facebook $(94.0 \%)$, were aged $50-64$ years $(83.7 \%)$ and women (85.7\%). Most participants were renting from a housing association (72.0\%) and had low education (61.0\%). Higher motivation to quit was statistically significantly associated with a higher intensity of previous quit attempts $(p=0.03)$, higher quit confidence $(p=0.01)$, higher smoking self-efficacy $(p=0.01)$, a lower riskminimising beliefs score $(p=0.01)$ and using traditional nicotine replacement therapy (NRT) when trying to stop smoking or cut down $(p<0.001)$.

Conclusion Older smokers from deprived backgrounds face complex barriers to quitting smoking. Interventions are needed to increase self-efficacy for quitting, modify risk-minimising beliefs and target elements of previous quit attempts (ie, the use of NRT) that are associated with motivation to stop smoking.

\section{INTRODUCTION}

Tobacco smoking is estimated to cause the premature deaths of approximately 6 million individuals worldwide and 96000 within the UK per year, ${ }^{1}$ resulting in an average of 10 life years lost. ${ }^{2}$ Smokers who do not stop smoking also begin to suffer diseases of old age around 10 years earlier in comparison to non-smokers. ${ }^{3}$ Most deaths related to smoking
Strengths and limitations of this study

- This research adds knowledge to the context of targeted smoking cessation interventions for a population who are at high risk of developing a variety of smoking related diseases, including lung cancer.

- An online survey, disseminated through Facebook advertising was useful for recruiting the target population.

- There was an under-representation of older individuals (ie, 65 years and older) and men.

- Due to the cross-sectional study design, caution is needed when interpreting associations with quit motivation.

arise from cancers, respiratory disease and cardiovascular disease. ${ }^{1}$ For example, lung cancer mortality is around 15 times higher in current smokers compared with neversmokers and increases with smoking amount and duration. ${ }^{4}$

Smoking is a major health inequality concern due to higher smoking rates among people from low socioeconomic groups in developed countries. The high prevalence of cigarette smoking among low socioeconomic groups demonstrates the striking relationship between social context and health behaviour. $^{56}$

Quit attempts by older smokers from deprived backgrounds are less likely to be successful due to higher levels of nicotine dependence and/or a lack of selfefficacy. $^{7}$ Research has indicated that smokers from deprived backgrounds find quitting more difficult due to having less social support when making a quit attempt. ${ }^{9}{ }^{10}$ Self-exempting beliefs, also known as risk-minimising beliefs, have also been shown to influence continued smoking among individuals from low socioeconomic groups. These beliefs may be adopted as a 
mechanism to help rationalise or justify smoking despite the well-known harms. ${ }^{11}$ Perceived risk of smokingrelated diseases, such as lung cancer, has been linked to smoking, with absolute and relative lung cancer risk perception being positively related to cigarette-smoking behaviours. ${ }^{12}$ Furthermore, previous research involving deprived smokers aged 40 years or older has found perceived lung cancer risk to be higher among this population compared with non-smokers. ${ }^{13}$

A systematic review of behavioural smoking cessation interventions indicated that offering incentives, use of peer facilitators and more intensive behavioural counselling are promising for encouraging smoking cessation in older smokers from deprived backgrounds. ${ }^{14}$ However, further evidence is needed regarding psychosocial targets for smoking cessation interventions aimed at this population. ${ }^{14}$

In this study, we aimed to identify modifiable psychosocial determinants of motivation to stop smoking among older smokers from socioeconomically deprived backgrounds. The selected survey measures were driven by a variety of theories, including the PRIME Theory of Motivation and the Extended Parallel Process Model. ${ }^{1516}$ It was anticipated that higher motivation to quit smoking would be associated with lower nicotine dependence, higher self-efficacy, higher perceived social support, lower selfexempting beliefs and higher perceived lung cancer risk. The evidence may be used to improve smoking cessation interventions for the target population.

\section{METHODS}

\section{Participants and recruitment methods}

Sample size was determined on the basis of (1) tobacco smoking rates in the UK population of older smokers ${ }^{17}$ and (2) expected response rate among smokers. ${ }^{18} 19$ Although we planned from the outset to measure the primary outcome of motivation to stop smoking on a 7-point scale, it was impossible to know in advance whether its conditional distribution, given predictors would allow analysis using linear regression. The decision was thus taken to calculate the sample size based on a dichotomisation of the outcome, which is conservative, given that dichotomisation decreases power. A sample of 300 respondents was chosen to provide $80 \%$ power to detect an OR of 2.0 in the dichotomised primary outcome at a $5 \%$ significance level. ${ }^{20}$

Participants were recruited to an online cross-sectional survey pragmatically and were current smokers, aged 50 years or more, from deprived backgrounds. Participants were given the option to be entered into a $£ 50$ shopping voucher prize draw and consented to be contacted if they won a voucher. A link to the online questionnaire was disseminated using Facebook, a population survey platform (HealthWise Wales: https://www.healthwisewales. gov.wales/) and a Wales based cancer charity (Tenovus Cancer Care). Snowball sampling was also used to recruit the target sample.
To determine eligibility, participants completed five questions based on socioeconomic deprivation, smoking status and age. Participants were eligible if they were $\geq 50$ years of age, a current smoker and met the threshold for at least two out of three individual-level deprivation indicators. Thresholds for deprivation indicators were: (1) education-educated to O level or Certificate of Secondary Education (CSE) equivalent (mostly grade D-G) or below; (2) household income-casual labourer, pensioner, student, unemployed (eg, pensioner without private pension and anyone living on basic benefits), semiskilled and unskilled manual worker, skilled manual worker and those with no previous or current employment within the household; (3) home ownershiprenting from local authority/housing association or living with family/friends.

\section{Patient and public involvement}

Public involvement was integrated according to national standards, ${ }^{21}$ and used during the development and design of the survey questions and structure. An appointed research partner presented feedback on the survey at various stages, including the final version prior to commencing recruitment. The research partner also assisted in the recruitment of participants for cognitive interviews used for survey development.

\section{Measures}

Cognitive interviews were first carried out with the target population to ascertain the suitability of the questionnaire. Interviews were conducted with five participants (three women and two men, aged 50-88 years) from a socioeconomically deprived area of South Wales. Content validity of unvalidated items was assessed by a panel of six academics with experience in the field of health behaviours. These steps were conducted in order to assess acceptability and comprehension of items, and resulted in adaptations to item wording and inclusion of selected items for the final version of the survey (online supplemental material).

\section{Demographic characteristics}

Data were collected on gender, age, relationship status, highest level of education, home ownership, household employment and comorbid conditions. ${ }^{22} \mathrm{~A}$ total score was created for the number of comorbid conditions, with a higher score indicating the presence of more comorbid conditions (score range $0-14$ ).

\section{Smoking characteristics}

Nicotine dependence was assessed using the Fagerstrom Test for Nicotine Dependence ${ }^{23}$ in order to create a total nicotine dependence score. Number of previous quit attempts ${ }^{24}$ and intensity of previous quit attempts (number of attempts combined with duration of the longest previous quit attempt) were also measured. Participants were asked whether they were currently trying to cut down and were asked to select multiple options from a list of smoking cessation aids (nicotine gum, lozenges, 
patches, inhalator, mouth spray, electronic cigarette, behavioural counselling or not using anything to help stop smoking).

\section{Motivation to stop smoking (primary outcome)}

The Motivation to Stop Scale (MTSS) ${ }^{25}$ is a validated measure that assesses the key elements of quit motivation: belief, desire and intention. ${ }^{15}$ The MTSS is a single-item instrument and assesses a smoker's motivation to stop smoking. The scale score ranged from 1 to $7: 1$ ) 'I don't want to stop smoking', 2) 'I think I should stop smoking but don't really want to', 3) 'I want to stop smoking but haven't thought about when', 4) 'I REALLY want to stop smoking but I don't know when I will', 5) 'I want to stop smoking and hope to soon', 6) 'I REALLY want to stop smoking and intend to in the next 3 months' and 7) 'I REALLY want to stop smoking and intend to in the next month'.

\section{Social support and smoking}

The social support and smoking questions ${ }^{26}$ measured how supported the participant felt during a previous quit attempt. Respondents were asked about various forms of social support experienced during a previous quit attempt, for example Encourage you to keep at quitting', 'Celebrate your quitting with you' and 'Say you were going to start smoking again'. Response options were rated on a scale of $1-5$ ( $1=$ never, $5=$ very often $)$. Principal components analysis (PCA) of the adapted social support items yielded two factor-derived subscales that were labelled positive smoking social support (eight items, $\alpha=0.85$ ) and negative smoking social support (three items, $\alpha=0.64$ ). Total possible score range for positive social support was $8-40$, with higher scores indicating higher positive social support during a previous quit attempt. Total possible score range for negative social support was 3-15, with higher scores indicating higher negative social support during a previous quit attempt. Participants were also asked how supported they felt by their partner, friends, colleague and general practitioner/healthcare professional during a previous quit attempt, with response options ranging from 1 to 5 ( $1=$ not at all, $5=$ extremely).

\section{Self-exempting beliefs}

The self-exempting beliefs measure comprises 16 items, with two subscales for self-exempting ('bulletproof') beliefs and risk-minimising ('jungle', 'sceptic' and 'worth it') beliefs. ${ }^{27}$ Examples of risk-minimising beliefs items included: 'Smoking cannot be all that bad for you because many people who smoke live long lives', 'I would rather live a shorter life and enjoy it than a longer one where I will be deprived of the pleasure of smoking' and 'You have got to die of something, so why not enjoy yourself and smoke'. Agreement with each item was rated on a scale of $1-5$ ( $1=$ totally disagree, $5=$ totally agree). Two factor-derived subscales labelled risk-minimising beliefs (five items, $\alpha=0.83$ ) and scepticism (two items, $\alpha=0.54$ ) were derived from the PCA. Total possible score ranges were 5-25 for the risk-minimising beliefs scale and 2-10 for the scepticism scale, with higher scores indicating higher levels of agreement.

\section{Smoking self-efficacy}

The eight-item smoking self-efficacy questionnaire ${ }^{28}$ was originally designed to measure current smokers' confidence in their ability to abstain from smoking in highrisk situations. The instrument presents participants with situations in which people might be tempted to smoke, such as when they feel nervous, depressed, angry, have the urge to smoke, are with other smokers and when they are having a tea or coffee. Participants responded on a 5-point Likert scale from 1 ('not at all sure') to 5 ('absolutely sure'). Total score range for this measure was 6 -30, with higher scores indicating greater smoking selfefficacy ( $\alpha=0.88$ ). After PCA, two items were removed and a smoking self-efficacy scale was created.

\section{Quit confidence}

Quit confidence was measured using a single item: ${ }^{29}$ 'How confident are you that you could quit smoking for good if you wanted to?'. The response options were on a scale of $1-5$ where $1=$ 'not at all' and $5=$ ='extremely'.

\section{Lung cancer experience}

Lung cancer experience was measured using seven items to assess personal experience of lung cancer as well as experience of social contacts (family, friends and member of community) ${ }^{30}$ Response options for this measure were 'yes', 'no', 'don't know' and 'prefer not to say'.

\section{Lung cancer risk perception}

Three items were used to assess lung cancer risk perception. ${ }^{31}$ Absolute risk perception was measured using the item 'How likely do you think it is that you will develop lung cancer in your lifetime?' with response options from 1 ('very unlikely') to 5 ('very likely'). Comparative risk perception was measured by asking 'Compared with others your age and sex, what do you think is your chance of getting lung cancer in your lifetime?' with response options from 1 to 5 ('much lower' to 'much higher'). Affective risk perception was measured using the question 'How worried are you about getting lung cancer in your lifetime?', with response options on a scale of 1 ('not at all') to 4 ('extremely').

\section{Statistical analyses}

Data were analysed using SPSS V.25. In order to deal with missing data in preparation for univariable and multivariable analysis, multiple imputation using chained equations was conducted on the original data set. ${ }^{32}$ All the incomplete variables were either dichotomous or (treated as) continuous. For each incomplete variable being imputed, all other variables were included in its imputation model. Where the incomplete variables were constituent parts of a composite score (eg, positive and negative social support scale), the imputation was performed on the individual questionnaire responses, 
and these imputed variables were then summed to create the imputed composite score. Those who responded with 'Don't know' to MTSS were removed from analysis.

PCA was used to identify the underlying factor structure of unvalidated measures (social support and smoking, self-exempting beliefs, smoking self-efficacy) that had been adapted on the basis of cognitive interviewing and content validity assessment.

Univariable associations between MTSS and demographic factors (age, gender, education, income, living situation, presence of comorbid conditions and lung cancer experience), smoking-related factors (nicotine dependence, previous quit attempts, smoking abstinence and smoking cessation aids) and psychosocial variables (self-efficacy, quit confidence, perceived social support for quitting, self-exempting beliefs and lung cancer risk perception) were assessed. Independent t-tests, Spearman's rank correlation and Pearson's correlation were used to test for univariable associations. A multivariable linear regression analysis was conducted, in which all variables were entered in a single step. CIs of 95\% were calculated for the associations between MTSS and variables that were statistically significant at $p \leq 0.05$ in univariable analyses.

MTSS was treated as a continuous variable, with a low score demonstrating an absence of any belief, desire or intention to stop smoking, and a high score demonstrating strong desire and short-term intention. Examination of the distribution of the outcome variable, and its mean and variance given predictors, suggested that a multivariable linear regression model was a suitable choice.

\section{RESULTS}

\section{Sample characteristics}

A total of 578 individuals consented to take part in the survey. Of those who consented, $278(48.1 \%)$ did not meet the inclusion criteria due to age $(n=2)$, smoking status $(n=24)$ and level of deprivation $(n=252)$. Of 300 eligible participants, most were recruited using Facebook advertising $(94.0 \%)$. The majority of participants were aged between 50 and 64 years $(83.7 \%)$ and women $(85.7 \%)$.

Almost half of the participants $(43.7 \%)$ reported that they did not want to stop smoking (table 1). Most participants had made a serious previous quit attempt (73.3\%) and were currently trying to cut down on how much they smoked (66.0\%). The most commonly used smoking cessation aid when trying to cut down/stop smoking was e-cigarettes $(28.3 \%)$, with over half the sample $(51.1 \%)$ not using anything to help them cut down/stop smoking.

\section{Univariable analysis of factors associated with motivation to stop smoking}

At univariable analysis, MTSS was significantly associated with 12 variables (tables 2 and 3). As depicted in table 2 , higher motivation to stop smoking was statistically significantly associated with lower nicotine dependence $(p=0.05)$, higher intensity of previous quit attempts $(p<0.001)$, currently trying to cut down on smoking $(\mathrm{p}<0.001)$, using a smoking cessation aid when trying to help cut down/quit smoking $(\mathrm{p}<0.001)$ and trying to cut down/quit without any smoking cessation aid $(\mathrm{p}=0.04)$ (table 2). Associations between MTSS and gender, age, relationship, education, employment, housing and comorbidity were not statistically significant.

As shown in table 3, higher motivation to stop smoking was statistically significantly associated with higher positive social support when making a quit attempt $(\mathrm{p}=0.04)$, higher smoking self-efficacy $(\mathrm{p}<0.001)$, higher quit confidence $(\mathrm{p}<0.001)$ and lower risk-minimising beliefs $(\mathrm{p}<0.001)$. Higher motivation to stop smoking was statistically significantly associated with higher perceived comparative $(\mathrm{p}=0.01)$ and affective $(\mathrm{p}<0.001)$ lung cancer risk, and having experienced lung cancer in a close friend $(\mathrm{p}=0.01)$.

\section{Multivariable regression of factors associated with motivation to stop smoking}

Conditional on all other predictors in the model, a unit increase in intensity of previous quit attempts was associated with an estimated 0.17 increase in MTSS ( $\mathrm{p}=0.03$, $95 \% \mathrm{CI}=0.02$ to 0.32 ). A unit increase for quit confidence was associated with an estimated 0.20 increase in MTSS ( $p=0.01,95 \% \mathrm{CI}=0.06$ to 0.35 ), self-efficacy was associated with an estimated 0.22 increase in MTSS ( $\mathrm{p}=0.01,95 \%$ $\mathrm{CI}=0.06$ to 0.37 ) and a unit increase in risk-minimising beliefs was associated with an estimated 0.18 decrease in MTSS ( $\mathrm{p}=0.01,95 \% \mathrm{CI}=0.04$ to 0.32 ). Those who reported using traditional nicotine replacement therapy (NRT) when trying to stop smoking or cut down scored on average a 0.26 higher MTSS score $(\mathrm{p}<0.001,95 \%$ CI $=0.12$ to 0.39 ) compared with those who did not (table 4).

\section{DISCUSSION}

To our knowledge, this is the first study to examine psychosocial determinants of quit motivation in a sample of older smokers aged 50+ years from deprived backgrounds. Higher motivation to quit was associated with higher intensity of previous quit attempts, higher quit confidence, higher smoking self-efficacy, lower riskminimising beliefs and using traditional NRT when trying to stop smoking or cut down.

Previous studies suggest that smokers from deprived backgrounds are equally motivated to try and quit smoking, but less likely to be successful during a quit attempt compared with more affluent smokers. ${ }^{33-36}$ This paradox results in lower quit rates and potentially exacerbates inequalities in the prevalence of smoking. An important factor that contributes to higher smoking rates among deprived smokers lies in the lack of research output that target this population ${ }^{37}$ and the general scarcity of literature for effective smoking cessation interventions for more disadvantaged smokers. ${ }^{38}$ 
Table 1 Sample characteristics $(n=300)$

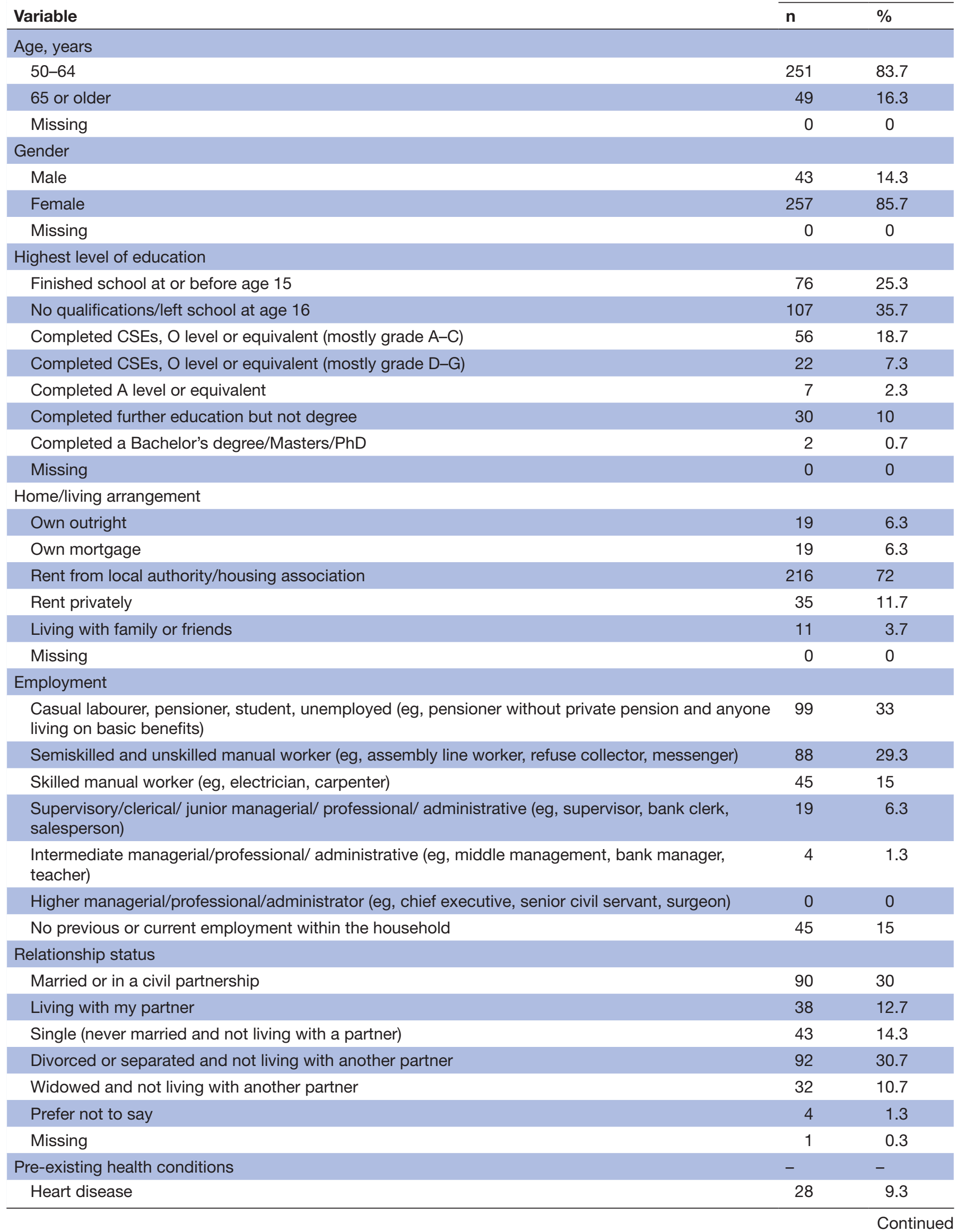

Descriptive statistic 
Table 1 Continued

\begin{tabular}{|c|c|c|}
\hline Variable & $\mathbf{n}$ & $\%$ \\
\hline High blood pressure & 65 & 21.7 \\
\hline Lung disease & 68 & 22.7 \\
\hline Diabetes & 43 & 14.3 \\
\hline An ulcer or stomach disease & 29 & 9.7 \\
\hline Kidney disease & 7 & 2.3 \\
\hline Liver disease & 5 & 1.7 \\
\hline Anaemia or other blood disease & 17 & 5.7 \\
\hline Cancer & 5 & 1.7 \\
\hline Depression & 154 & 51.3 \\
\hline Osteoarthritis or degenerative arthritis & 90 & 30 \\
\hline Back pain & 167 & 55.7 \\
\hline Rheumatoid arthritis & 42 & 14 \\
\hline \multicolumn{3}{|l|}{ Motivation to stop smoking } \\
\hline I don’t want to stop smoking & 41 & 13.7 \\
\hline I think I should stop smoking but don't really want to & 90 & 30.0 \\
\hline I want to stop smoking but haven't thought about when & 40 & 13.3 \\
\hline I REALLY want to stop smoking but don't know when I will & 64 & 21.3 \\
\hline I want to stop smoking and hope to soon & 19 & 6.3 \\
\hline I REALLY want to stop smoking and intend to in the next 3 months & 14 & 4.7 \\
\hline I REALLY want to stop smoking and intend to in the next month & 16 & 5.3 \\
\hline Don't know* & 16 & 5.3 \\
\hline \multicolumn{3}{|l|}{ Previous serious quit attempt } \\
\hline Yes & 220 & 73.3 \\
\hline No & 79 & 26.3 \\
\hline Missing & 1 & 0.3 \\
\hline \multicolumn{3}{|l|}{ Currently trying to cut down smoking } \\
\hline Yes & 198 & 66.0 \\
\hline No & 100 & 33.3 \\
\hline Missing & 2 & 0.7 \\
\hline \multicolumn{3}{|l|}{ Smoking cessation aids ( $n=198$ ) } \\
\hline Nicotine gum & 4 & 1.8 \\
\hline Nicotine lozenge & 5 & 2.3 \\
\hline Nicotine patch & 14 & 6.4 \\
\hline Nicotine inhaler/inhalator & 6 & 2.7 \\
\hline Another nicotine product & 3 & 1.4 \\
\hline Electronic cigarette & 62 & 28.3 \\
\hline Nicotine mouth spray & 3 & 1.4 \\
\hline Behavioural counselling (eg, group sessions, telephone support, individual support) & 2 & 0.9 \\
\hline I am not using anything to help me stop smoking & 112 & 51.1 \\
\hline
\end{tabular}

*Participants who responded 'Don't know' were removed from further analysis.

CSE, certificate of secondary education.

The current findings suggest that the salient determinant of quit motivation in the target population was the use of traditional NRT (eg, patches, gum and lozenges) during a previous attempt to cut down or quit smoking. Use of NRT has been shown to increase cessation success ${ }^{39}$ and is more effective at promoting cessation in older age 
Table 2 Univariable associations between motivation to stop smoking and demographic/smoking characteristics $(\mathrm{n}=284)$

\begin{tabular}{|c|c|c|c|c|}
\hline Variable & $\mathbf{n}$ & $\begin{array}{l}\text { MTSS mean } \\
\text { (SD) }\end{array}$ & $\begin{array}{l}\text { Test statistic/correlation } \\
\text { coefficient }\end{array}$ & $P$ value \\
\hline \multicolumn{5}{|l|}{ Gender* } \\
\hline Female & 243 & $3.14(1.62)$ & 0.22 & 0.82 \\
\hline Male & 41 & $3.07(1.84)$ & & \\
\hline \multicolumn{5}{|l|}{ Age, years* } \\
\hline $50-64$ & 239 & $3.10(1.65)$ & -0.72 & 0.47 \\
\hline $65+$ & 45 & $3.29(1.69)$ & & \\
\hline \multicolumn{5}{|l|}{ Relationship* } \\
\hline Widowed/divorced/single & 161 & $3.14(1.65)$ & 0.14 & 0.89 \\
\hline Married/living with a partner & 120 & $3.11(1.66)$ & & \\
\hline Missing data & 5 & & & \\
\hline \multicolumn{5}{|l|}{ Education* $^{\star}$} \\
\hline Lower education & 193 & $3.11(1.62)$ & -0.27 & 0.79 \\
\hline Higher education & 91 & $3.16(1.72)$ & & \\
\hline \multicolumn{5}{|l|}{ Employment* } \\
\hline Lower employment level & 262 & $3.13(1.64)$ & 0.24 & 0.81 \\
\hline Higher employment level & 22 & $3.05(1.81)$ & & \\
\hline \multicolumn{5}{|l|}{ Housing ${ }^{*}$} \\
\hline Own house/mortgage/rent privately & 70 & $3.36(1.70)$ & 1.35 & 0.18 \\
\hline $\begin{array}{l}\text { Rent from housing association/living with friends } \\
\text { or family }\end{array}$ & 214 & $3.05(1.63)$ & & \\
\hline Comorbidity score $†$ & 284 & & 0 & 0.97 \\
\hline Nicotine dependence score $†$ & 284 & & -0.11 & 0.05 \\
\hline Intensity of previous quit attempt score $†$ & 209 & & 0.26 & $<0.001$ \\
\hline \multicolumn{5}{|l|}{ Currently trying to cut down on smoking* } \\
\hline Yes & 185 & $3.44(1.57)$ & 4.53 & $<0.001$ \\
\hline No & 97 & $2.54(1.64)$ & & \\
\hline \multicolumn{5}{|c|}{ Using traditional nicotine replacement therapies to help cut down/quit* } \\
\hline Yes & 23 & $4.87(1.55)$ & -4.95 & $<0.001$ \\
\hline No & 162 & $3.24(1.47)$ & & \\
\hline \multicolumn{5}{|l|}{ Using electronic cigarette to help cut down/quit* } \\
\hline Yes & 58 & $3.21(1.46)$ & 1.37 & 0.17 \\
\hline No & 226 & $3.55(1.61)$ & & \\
\hline \multicolumn{5}{|c|}{ Trying to cut down/quit without any smoking cessation aid* } \\
\hline Yes & 104 & $3.23(1.44)$ & 2.07 & 0.04 \\
\hline No & 81 & $3.72(1.70)$ & & \\
\hline
\end{tabular}

*Independent t-test.

†Pearson's correlation coefficient.

MTSS, Motivation to Stop Scale.

groups compared with younger groups. ${ }^{40}{ }^{41}$ Our findings confirm that NRT is an important tool in encouraging motivation to stop smoking in older smokers from deprived backgrounds. However, evidence for which type of NRT works best for this population is limited and the provision of NRT may need to be tailored in order to fit the needs and preferences of this population.
Previous studies have found deprived smokers to be less likely to use NRTs and that one of the barriers to quitting includes inability to access treatment. ${ }^{42}$ Making NRTs easily available to this population could increase their motivation to stop smoking and encourage older smokers from deprived backgrounds to make serious quit attempts that are more likely to be successful. Although 
Table 3 Univariable associations between motivation to stop smoking and psychosocial variables

\begin{tabular}{|c|c|c|c|c|}
\hline Variable & $\mathbf{n}$ & $\begin{array}{l}\text { MTSS mean } \\
\text { (SD) }\end{array}$ & $\begin{array}{l}\text { Test statistic/correlation } \\
\text { coefficient }\end{array}$ & $P$ value \\
\hline Psychological variables & & & & - \\
\hline Risk-minimising beliefs* & 284 & - & -0.27 & $<0.001$ \\
\hline Scepticism* ${ }^{*}$ & 284 & - & -0.07 & 0.26 \\
\hline Quit confidence† & 284 & - & 0.4 & $<0.001$ \\
\hline Smoking self-efficacy* & 284 & - & 0.21 & $<0.001$ \\
\hline \multicolumn{5}{|l|}{ Smoking and social support during a previous quit attempt } \\
\hline Someone to turn during a quit attempt $\dagger$ & & - & -0.04 & 0.53 \\
\hline Positive smoking social support* & 211 & - & 0.14 & 0.04 \\
\hline Negative smoking social support ${ }^{\star}$ & 210 & - & -0.01 & 0.91 \\
\hline Support from partner during previous quit attempt $\dagger$ & 180 & - & -0.01 & 0.89 \\
\hline Support from family during previous quit attempt $\dagger$ & 200 & - & 0.03 & 0.63 \\
\hline Support from friends during previous quit attempt $†$ & 198 & - & 0.01 & 0.92 \\
\hline Support from colleagues during previous quit attempt $\dagger$ & 187 & - & 0 & 0.96 \\
\hline $\begin{array}{l}\text { Support from general practitioner or healthcare professional during } \\
\text { previous quit attempt } \dagger\end{array}$ & 188 & - & -0.06 & 0.44 \\
\hline Someone to turn during if finding quitting difficult $\dagger$ & 284 & - & -0.04 & 0.53 \\
\hline \multicolumn{5}{|l|}{ Lung cancer experienceł } \\
\hline Self & & & & - \\
\hline Yes & 19 & $3.19(1.85)$ & 0.22 & 0.83 \\
\hline No & 246 & $3.08(1.63)$ & & \\
\hline \multicolumn{5}{|l|}{ Partner } \\
\hline Yes & 19 & $3.58(2.10)$ & 0.77 & 0.45 \\
\hline No & 223 & $3.13(1.64)$ & & \\
\hline \multicolumn{5}{|l|}{ Close family member } \\
\hline Yes & 98 & $3.30(1.58)$ & 1.13 & 0.26 \\
\hline No & 157 & $3.05(1.65)$ & & \\
\hline \multicolumn{5}{|l|}{ Other family member } \\
\hline Yes & 63 & $3.29(1.56)$ & 1.38 & 0.17 \\
\hline No & 174 & $2.96(1.58)$ & & \\
\hline \multicolumn{5}{|l|}{ Close friend } \\
\hline Yes & 63 & $3.62(1.68)$ & 2.78 & 0.01 \\
\hline No & 173 & $2.88(1.62)$ & & \\
\hline \multicolumn{5}{|l|}{ Other friend } \\
\hline Yes & 53 & $3.34(1.60)$ & 1.42 & 0.16 \\
\hline No & 174 & $2.96(1.55)$ & & \\
\hline \multicolumn{5}{|l|}{ A member of your community } \\
\hline Yes & 87 & $3.29(1.66)$ & 1.84 & 0.07 \\
\hline No & 124 & $2.87(1.52)$ & & \\
\hline \multicolumn{5}{|l|}{ Lung cancer risk perception† } \\
\hline Absolute risk & 284 & - & 0.11 & 0.08 \\
\hline Comparative risk & 284 & - & 0.15 & 0.01 \\
\hline Affective risk & 284 & - & 0.36 & $<0.001$ \\
\hline
\end{tabular}

*Pearson's correlation coefficient. †Spearman's rank correlation coefficient. ¥ Independent t-test.

MTSS, Motivation to Stop Scale. 
Table 4 Multivariable associations with motivation to stop smoking

\begin{tabular}{|c|c|c|c|c|}
\hline Variable & $\begin{array}{l}\text { Estimated adjusted } \\
\text { mean difference }\end{array}$ & SE & $95 \% \mathrm{Cl}$ & $P$ value \\
\hline Intensity of previous quit attempts & 0.17 & 0.08 & 0.02 to 0.32 & 0.03 \\
\hline Currently trying to cut down on smoking & -0.02 & 0.31 & -0.20 to 0.16 & 0.81 \\
\hline Positive social support during a previous quit attempt & 0.00 & 0.02 & -0.14 to 0.14 & 1.00 \\
\hline Smoking self-efficacy & 0.22 & 0.03 & 0.06 to 0.37 & 0.01 \\
\hline Quit confidence & 0.20 & 0.10 & 0.06 to 0.35 & 0.01 \\
\hline Risk-minimising beliefs & -0.18 & 0.03 & -0.32 to 0.04 & 0.01 \\
\hline Close friend with a diagnosis of lung cancer & 0.13 & 0.26 & -0.01 to 0.26 & 0.07 \\
\hline Comparative lung cancer risk & -0.04 & 0.15 & -0.18 to 0.11 & 0.64 \\
\hline Affective lung cancer risk & 0.12 & 0.10 & -0.02 to 0.27 & 0.10 \\
\hline $\begin{array}{l}\text { Using traditional nicotine replacement therapies to help } \\
\text { cut down/quit* }\end{array}$ & 0.26 & 0.43 & 0.12 to 0.39 & $<0.001$ \\
\hline Not using any smoking cessation aids to help cut down* & 0.02 & 0.27 & -0.14 to 0.18 & 0.78 \\
\hline Nicotine dependence & 0.06 & 0.05 & -0.08 to 0.20 & 0.30 \\
\hline
\end{tabular}

*Dichotomous variable (coded yes/no).

an association between quit motivation and the presence of comorbid conditions was not observed in the current study, it has been proposed that smoking cessation interventions (specifically NRTs) for older adults should be personalised due to the presence of comorbidities and medication that can reduce the use and effectiveness of NRT. $^{43}$

Furthermore, the current research suggests that a higher intensity of previous quit attempts is associated with higher motivation to stop smoking. Future interventions should focus on encouraging the target population to persist with their quit attempts as well as promote the use of behavioural support and NRT in order to improve motivation to quit.

The current study further illustrates the importance of quitting self-efficacy in relation to improving motivation to stop smoking among older smokers from deprived backgrounds. Previous research from Siahpush $e t a t^{44}$ showed that low self-efficacy can explain the lower smoking cessation rate observed among low socioeconomic smokers. Individuals from deprived backgrounds are more likely to be exposed to stressful and disadvantaged lives and have less access to material and social resources, which, in turn, can reduce self-efficacy and motivation to stop smoking. ${ }^{45} 46$

Risk-minimising beliefs may be adopted in order to justify continued smoking despite the risks to health. ${ }^{27} 47$ Similarly, previous studies indicate that individuals from socially deprived backgrounds are more likely to hold self-exempting beliefs. ${ }^{27}$ 47-49 Older smokers who have previously been shown to hold these beliefs consider themselves as 'survivors', resulting in a lower motivation to stop smoking. ${ }^{1}$

Methodological limitations of the current study are acknowledged. Although we were able to demonstrate representation of smokers from a low socioeconomic background in the sample there are issues of generalisability. Men and those aged 65 years or older were underrepresented, which could be due to older adults being less likely to have access to social media or the internet ${ }^{50}$ and men being traditionally more difficult to recruit to research. ${ }^{51}$ Due to the cross-sectional study design, caution is needed when interpreting associations due to shared-method variance and inability to infer causal relationships. ${ }^{52}$ Further limitations include the variable internal validity of factor-derived subscales and the use of self-reported measures. Suitable validated measures are needed to better capture evidence of psychosocial influences on smoking behaviour in older smokers from deprived backgrounds.

This research is valuable in the context of targeted smoking cessation interventions for a population who are at high risk of developing a variety of smoking-related diseases, including lung cancer. The target population face a breadth of complex barriers to quitting smoking and interventions are needed to increase self-efficacy for quitting, dispel risk-minimising beliefs and target elements of previous quit attempts (ie, NRTs used) that are associated with motivation to stop smoking. Findings from this research could be used in the adaptation of behavioural smoking cessation interventions by addressing identified psychosocial determinants. This has the potential to improve quit motivation and could encourage a smoking cessation attempt in older smokers from deprived backgrounds.

Twitter Annmarie Nelson @annmarie0

Contributors PS, KB, AN, RLM and GM were responsible for the concept, overall design and conduct of the study. RD gave additional support and advice on multiple imputation for missing data and statistical analysis. PS was responsible for collection of data and manuscript preparation. All authors were involved in the interpretation of the results and approved the final version of the manuscript. 
Funding This study was funded by School of Medicine, Cardiff University. AN's post was supported by Marie Curie core grant funding (grant reference: MCCCFCO11-C). The work was also conducted under the auspices of the Wales Cancer Research Centre (Health and Care Research Wales grant reference: 517190).

Competing interests None declared.

Patient consent for publication Not required.

Ethics approval The study received ethical approval from Cardiff University School of Medicine (SMREC Reference Number: 19/06)

Provenance and peer review Not commissioned; externally peer-reviewed.

Data availability statement All data relevant to the study are included in the article or uploaded as supplemental information.

Supplemental material This content has been supplied by the author(s). It has not been vetted by BMJ Publishing Group Limited (BMJ) and may not have been peer-reviewed. Any opinions or recommendations discussed are solely those of the author(s) and are not endorsed by BMJ. BMJ disclaims all liability and responsibility arising from any reliance placed on the content. Where the content includes any translated material, BMJ does not warrant the accuracy and reliability of the translations (including but not limited to local regulations, clinical guidelines, terminology, drug names and drug dosages), and is not responsible for any error and/or omissions arising from translation and adaptation or otherwise.

Open access This is an open access article distributed in accordance with the Creative Commons Attribution Non Commercial (CC BY-NC 4.0) license, which permits others to distribute, remix, adapt, build upon this work non-commercially, and license their derivative works on different terms, provided the original work is properly cited, appropriate credit is given, any changes made indicated, and the use is non-commercial. See: http://creativecommons.org/licenses/by-nc/4.0/.

\section{ORCID iDs}

Pamela Smith http://orcid.org/0000-0002-0336-215X

Rachael L Murray http://orcid.org/0000-0001-5477-2557

Kate Brain http://orcid.org/0000-0001-9296-9748

\section{REFERENCES}

1 Action on smoking and health, 2016. Available: http://ash.org.uk/ information-and-resources/fact-sheets/smoking-statistics-whosmokes-and-how-much/

2 Office of the Surgeon G, Office on S, Health. Reports of the surgeon General. The health consequences of smoking: a report of the surgeon General. Atlanta (GA): Centers for Disease Control and Prevention (US), 2004.

3 Jha P, Peto R. Global effects of smoking, of quitting, and of taxing tobacco. N Engl J Med 2014;370:60-8.

4 Doll R, Peto R, Boreham J, et al. Mortality from cancer in relation to smoking: 50 years observations on British doctors. $\mathrm{Br} \mathrm{J}$ Cancer 2005;92:426-9.

5 Cavelaars AE, Kunst AE, Geurts JJ, et al. Educational differences in smoking: international comparison. BMJ 2000;320:1102-7.

6 Huisman M, Kunst AE, Mackenbach JP. Inequalities in the prevalence of smoking in the European Union: comparing education and income. Prev Med 2005;40:756-64.

7 Benowitz NL. Nicotine addiction. N Engl J Med 2010;362:2295-303.

82008 PHS Guideline Update Panel, Liaisons, and Staff. Treating tobacco use and dependence: 2008 update U.S. public health service clinical practice guideline executive summary. Respir Care 2008;53:1217-22.

9 Chandola T, Head J, Bartley M. Socio-Demographic predictors of quitting smoking: how important are household factors? Addiction 2004;99:770-7.

10 Lacey LP, Manfredi C, Balch G, et al. Social support in smoking cessation among black women in Chicago public housing. Public Health Rep 1993;108:387-94.

11 Guillaumier A, Bonevski B, Paul C, et al. Self-Exempting beliefs and intention to quit smoking within a socially disadvantaged Australian sample of smokers. Int J Environ Res Public Health 2016;13:118.

12 Chen L-S, Kaphingst KA, Tseng T-S, et al. How are lung cancer risk perceptions and cigarette smoking related?-testing an accuracy hypothesis. Trans/ Cancer Res 2016;5:S964-71.

13 Quaife SL, Marlow LAV, McEwen A, et al. Attitudes towards lung cancer screening in socioeconomically deprived and heavy smoking communities: informing screening communication. Health Expect 2017;20:563-73.
14 Smith P, Poole R, Mann M, et al. Systematic review of behavioural smoking cessation interventions for older smokers from deprived backgrounds. BMJ Open 2019;9:e032727.

15 West R, Brown J. Theory of addiction. Chichester, West Sussex. UK: Wiley Blackwell/Addiction Press, 2014.

16 Witte K. Putting the fear back into fear appeals: the extended parallel process model. Commun Monogr 1992;59:329-49.

17 Office for national Statistics- adults smoking habits in the UK 2017. Available: https://www.ons.gov.uk/peoplepopulationandcommunity/ healthandsocialcare/healthandlifeexpectancies/bulletins/adultsmo kinghabitsingreatbritain/2017

18 Brodar KE, Hall MG, Butler EN, et al. Recruiting diverse smokers: enrollment yields and cost. Int J Environ Res Public Health 2016;13. doi:10.3390/ijerph13121251. [Epub ahead of print: 16 Dec 2016].

19 Thompson TP, Aveyard P, Ayres R, et al. Strategies to recruit hardto-reach smokers into exercise assisted reduction then stop (ears): a pragmatic pilot randomised trial. The Lancet 2012;380:S73.

20 Dupont WD, Plummer WD. Power and sample size calculations for studies involving linear regression. Control Clin Trials 1998;19:589-601.

21 NIHR. National standards for public involvement (website), 2018. Available: https://sites.google.com/nihr.ac.uk/pi-standards/home [Accessed 10 Jun 2018].

22 Sangha O, Stucki G, Liang MH, et al. The self-administered comorbidity questionnaire: a new method to assess comorbidity for clinical and health services research. Arthritis Rheum 2003;49:156-63.

23 Heatherton TF, Kozlowski LT, Frecker RC, et al. The Fagerström test for nicotine dependence: a revision of the Fagerström tolerance questionnaire. Br J Addict 1991;86:1119-27.

24 The smoking toolkit study. Available: http://www.smokinginengland. info/sts-documents/ [Accessed Sep 2018].

25 Kotz D, Brown J, West R. Predictive validity of the motivation to stop scale (MTSS): a single-item measure of motivation to stop smoking. Drug Alcohol Depend 2013;128:15-19.

26 NCSCT. National centre for smoking cessation and training. Available: https://www.ncsct.co.uk/usr/pub/Social\%20support.pdf [Accessed Sep 2018].

27 Oakes W, Chapman S, Borland R, et al. "Bulletproof skeptics in life's jungle": which self-exempting beliefs about smoking most predict lack of progression towards quitting? Prev Med 2004;39:776-82.

28 Etter JF, Bergman MM, Humair JP, et al. Development and validation of a scale measuring self-efficacy of current and former smokers. Addiction 2000;95:901-13.

29 Kaufman AR, Coa KI, Nguyen AB. Cigarette smoking risk-reducing beliefs: findings from the United States health information national trends survey. Prev Med 2017;102:39-43.

30 UK CR. Lung cancer awareness measure (lung cam) toolkit. Available: https://www.cancerresearchuk.org/sites/default/files/ health_professional_lung_cam_toolkit_version_2.1_09.02.11.pdf

31 Kaufman AR, Koblitz AR, Persoskie A, et al. Factor structure and stability of smoking-related health beliefs in the National lung screening trial. Nicotine Tob Res 2016;18:321-9.

32 van Buuren S, Boshuizen HC, Knook DL. Multiple imputation of missing blood pressure covariates in survival analysis. Stat Med 1999;18:681-94.

33 Caleyachetty A, Lewis S, McNeill A, et al. Struggling to make ends meet: exploring pathways to understand why smokers in financial difficulties are less likely to quit successfully. Eur J Public Health 2012;22 Suppl 1:41-8.

34 Hiscock R, Judge K, Bauld L. Social inequalities in quitting smoking: what factors mediate the relationship between socioeconomic position and smoking cessation? J Public Health 2011;33:39-47.

35 Kotz D, Fidler J, West R. Factors associated with the use of AIDS to cessation in English smokers. Addiction 2009;104:1403-10.

36 Levy DT, Romano E, Mumford E. The relationship of smoking cessation to sociodemographic characteristics, smoking intensity, and tobacco control policies. Nicotine Tob Res 2005;7:387-96. doi:10.1080/14622200500125443

37 Courtney RJ, Naicker S, Shakeshaft A, et al. Smoking cessation among Low-Socioeconomic status and disadvantaged population groups: a systematic review of research output. Int J Environ Res Public Health 2015;12:6403-22.

38 Bryant J, Bonevski B, Paul C, et al. A systematic review and metaanalysis of the effectiveness of behavioural smoking cessation interventions in selected disadvantaged groups. 2011;106:1568-85.

39 Stead LF, Perera R, Bullen C, et al. Nicotine replacement therapy for smoking cessation. Cochrane Database Syst Rev 2012;11:CD000146. 
40 Cawkwell PB, Blaum C, Sherman SE. Pharmacological smoking cessation therapies in older adults: a review of the evidence. Drugs Aging 2015;32:443-51.

41 Scholz J, Santos PCJL, Buzo CG, et al. Effects of aging on the effectiveness of smoking cessation medication. Oncotarget 2016;7:30032-6.

42 Roddy E, Romilly N, Challenger A, et al. Use of nicotine replacement therapy in socioeconomically deprived young smokers: a community-based pilot randomised controlled trial. Tob Control 2006;15:373-6.

43 Appel DW, Aldrich TK. Smoking cessation in the elderly. Clin Geriatr Med 2003;19:77-100.

44 Siahpush M, McNeill A, Borland R, et al. Socioeconomic variations in nicotine dependence, self-efficacy, and intention to quit across four countries: findings from the International tobacco control (ITC) four country survey. Tob Control 2006;15 Suppl 3:iii71-5.

45 Businelle MS, Kendzor DE, Reitzel LR, et al. Mechanisms linking socioeconomic status to smoking cessation: a structural equation modeling approach. Health Psychol 2010;29:262-73.

46 Turner LR, Mermelstein R, Hitsman B, et al. Social support as a moderator of the relationship between recent history of depression and smoking cessation among lower-educated women. Nicotine Tob Res 2008;10:201-12.

47 Borland $\mathrm{R}$, Yong $\mathrm{H}-\mathrm{H}$, Balmford J, et al. Do risk-minimizing beliefs about smoking inhibit quitting? findings from the International tobacco control (ITC) Four-Country survey. Prev Med 2009;49:219-23.

48 Chapman S, Wong WL, Smith W. Self-exempting beliefs about smoking and health: differences between smokers and ex-smokers. Am J Public Health 1993;83:215-9.

49 Peretti-Watel P, Halfen S, Grémy I. Risk denial about smoking hazards and readiness to quit among French smokers: an exploratory study. Addict Behav 2007;32:377-83.

50 Office for National Statistics. Exploring the UK's digital divide. The scale of digital exclusion in the UK; those who aren't currently using the internet, how digital skills vary for different groups of the population and some of the barriers to digital inclusion, 2019.

51 Ryan J, Lopian L, Le B, et al. It's not raining men: a mixed-methods study investigating methods of improving male recruitment to health behaviour research. BMC Public Health 2019;19:814.

52 Setia MS. Methodology series module 3: cross-sectional studies. Indian J Dermatol 2016;61:261-4. 